\title{
MODEL LATIHAN KETERAMPILAN SHOOTING OLAHRAGA PETANQUE UNTUK PEMULA
}

\author{
Tri Sutrisna, ${ }^{1}$ Moch Asmawi, ${ }^{2}$ Ramdan Pelana ${ }^{3}$ \\ Universitas Negeri Jakartal, Universitas Negeri Jakarta2, Universitas Negeri Jakarta ${ }^{3}$ \\ trizna.fik@gmail.com, asmawi.moch@yahoo.co.id, ramdanpelana@unj.ac.id
}

\begin{abstract}
Abstrak. Tujuan dari penelitian dan pengembangan ini adalah untuk menghasilkan model latihan keterampilan shooting olahraga petanque untuk pemula. Selain itu, penelitian dan pengembangan ini dilakukan untuk memperoleh informasi secara mendalam tentang pengembangan dan penerapan model latihan keterampilan shooting olahraga petanque untuk pemula dan mengetahui efektivitas, efisiensi serta daya tarik anak terhadap model yang dibuat. Penelitian ini menggunakan metode penelitian pengembangan Research \& Development (R \& D) dari Borg and Gall. Subyek dalam penelitian dan pengembangan ini adalah siswa SMA dan SMK DKI Jakarta yang terdiri dari 30 anak.

Instrumen yang digunakan dalam penelitian dan pengembangan ini adalah angket, kuisioner, serta instrumen test menembakkan bola ke sasaran (shooting) olahraga petanque yang digunakan untuk mengumpulkan datavhasil shooting atlet pemula, adapun tahapan dalam penelitian dan pengembangan ini adalah, pada tahap: (1) analisis kebutuhan, (2) evaluasi ahli (evaluasi produk awal); (3) ujicoba terbatas (ujicoba kelompok kecil); dan (4) ujicoba utama (field testing). Uji efektifitas model menggunakan test menembakkan bola ke sasaran (shooting) untuk mengetahui tingkat kemampuan shooting olahraga petanque untuk pemula sebelum pemberian treatmen berupa model latihan shooting yang dikembangkan dan untuk mengetahui tingkat kemampuan shooting setelah perlakuan atau treatmen model latihan shooting yang dikembangkan, dari tes awal yang dilakukan diperoleh tingkat shooting atlet/siswa sebesar 11.87, kemudian setelah diberikan perlakuan berupa model latihan shooting diperoleh tingkat kemampuan shooting atlet/siswa sebesar 18.57. Maka model latihan shooting olahraga petanque ini efektif dalam meningkatkan latihan shooting olahraga olahraga petanque untuk pemula.

Berdasarkan hasil pengembangan dapat disimpulkan bahwa: (1) Dengan model latihan keterampilan shooting olahraga petanuqe untuk pemula dapat dikembangkan dan diterapkan dalam latihan ekstrakurikuler di sekolah (2) Dengan model latihan shooting olahraga petanque untuk pemula yang telah dikembangkan, diperoleh bukti adanya peningkatan ini ditunjukan pada hasil pengujian data hasil pretes dan posttest adanya perbedaan yang signifikan antara sebelum dan sesudah adanya perlakuan model.
\end{abstract}

Keywords: Pengembangan, model, shooting. 


\section{PENDAHULUAN}

Hasil dari pengamatan para pelatih di sekolah juga menunjukan kurangnya tingkat akurasi atlet pemula yaitu rata-rata saat melakukan shooting dengan kesempatan 50 bola atlet tersebut hanya sekitar 10-15 target yang tepat sasaran, hal ini juga diperkuat oleh fakta yang menunjukkan pada saat bertanding atlet cenderung sering melakukan teknik pointing saja dibandingkan shooting padahal saat kondisi tertentu atlet harus menggunakan teknik shooting, dari catatan pertandingan pun rata-rata dari 20 kesempatan shooting atlet hanya mampu mendapatkan 5 yang tepat sasaran. Perlu dilakukannya model latihan keterampilan shooting agar atlet pemula akan menyukai dan bahkan menguasai keterampilan shooting, ditambah lagi cabang olahraga ini terdapat satu nomor pertandingan yang disebut dengan shooting pretition, dimana atlet hanya melakukan shooting tanpa melakukan pointing.

Nomor pertandingan ini pula yang dapat mengharumkan nama Indonesia pada ajang Sea Games Singapure tahun 2015 saat itu Indonesia berhasil memperoleh medali perak. Untuk itu peneliti berinisistif melakukan inovasi dengan melakukan penelitian yang berjudul 'Pengembangan Model Latihan Keterampilan Shooting Olahraga Petanque Untuk Atlet Pemula'. Peneliti bertujuan agar semakin banyaknya variasi latihan yang dilakukan atlet pemula sehingga atlet pemula tidak merasa bosan dengan metode latihan yang monoton, khususnya keterampilan shooting. Peneliti juga bertujan agar dengan penelitian ini makin banyak atlet-atlet yang nantinya dapat mengharumkan nama Indonesia di kancah international.

\section{Keterampilan}

Keterampilan secara sederhana didefinisikan sebagai suatu kemampuan untuk melaksanakan tugas yang memiliki tujuan spesifik yang ingin dicapai. Sedangkan William H. Edwards mendefenisikan keterampilan adalah sebagai ukuran kesuksesan dari kualitas gerakan dan menghasilkan gerak konstan yang benar untuk mencapai tujuan tertentu. Jadi keterampilan ialah kemampuan seseorang untuk melakukan gerakan dengan tujuan.

Menurut Guthrie, keterampilan terdiri dari kemampuan untuk menghasilkan hasil akhir dengan kepastian maksimum dan pengeluaran energi minimum atau waktu dan energi, gerakan yang dilakukan dengan tujuan yang diinginkan dalam pikiran.

Keterampilan digunakan untuk menggambarkan gerakan motorik seseorang yang telah mencapai keunggulan dalam aktivitasnya. Seorang atlet yang dianggap terampil sering memiliki kualitas koordinasi, kemampuan, kontrol, dan efisiensi gerak. Belajar keterampilan gerak, memiliki karakteristik berbeda dengan belajar kognitif dan afektif. Singer mengutip pendapat Fitts dan Posner bahwa ada tiga tahap yang harus dilakukan oleh seseorang yang belajar keterampilan gerak, yaitu: (1) tahap kognitif, (2) tahap asosiatif, dan (3) tahap otomatisasi.

Olahraga petanque adalah olahraga ketangkasan dalam melempar bola yang terbuat dari besi dengan mendekatkan bola target dan menjauhkan bola lawan (target) atau biasa disebut shooting, serta kedua kaki berada di dalam lingkaran. Bentuk asli olahraga ini muncul pada tahun 1907 di La Ciotat, di Provence, kota di selatan Perancis saat itu olahraga petanque dimainkan hanya oleh para bangsawan Perancis, seiring berkembangnya zaman petanque mulai di mainkan oleh semua kalangan dan sampai saat ini petaque merupakan olahraga prestasi yang 
dipertandingkan dihampir semua negara maju di seluruh benua.

Olahraga petanque merupakan olahraga yang baru berkembang di Indonesia, namun Indonesia sendiri mengenal olahraga petanque sejak lama dan tidak diketahui tahun pastinya. Di Indonesia, olahraga ini hanya dimainkan oleh kaum ekspatriat/orang-orang asing yang bekerja di Indonesia melalui perkumpulan-perkumpulan ekspatriat seperti International Sport Club Indonesia (ISCI) di Ciputat Jakarta dan Jakarta Petanque Club (JPC) di Ragunan Jakarta.

Olahraga petanque dapat dimainkan dimana saja, asal berada di atas tanah keras, tetapi tidak direkomendasikan bermain di atas rumput atau beton. Petanque mensyaratkan adanya spin bola untuk menghentikan bola yang menggelinding. Keterampilan dasar olahraga petanque adalah melempar, dimana ada 2 (dua) jenis lemparan dalam olahraga petanque: pointing dan shooting. Di dalam melakukan keterampilan pointing yang benar, bosi dipegang dengan seluruh telapak tangan dan terkepal tanpa ada ruang pada ruas jari-jari. Sehingga hasil lemparan dapat sempurna dan mencapai sasaran yang diinginkan. Pointing adalah jenis lemparan untuk mendekati boka target lebih dekat dari bosi lawan. Shooting adalah jenis lemparan untuk mengusir bosi lawan dari boka target.

Shooting merupakan salah satu teknik dasar lemparan dalam olahraga petanque, untuk mengusir bosi lawan dari boka target. Teknik ini diperlukan ketika bosi lawan dekat dengan boka. Esensi tingkat kesulitan teknik shooting dipengaruhi pula dengan posisi tubuh, posisi kaki yang harus stabil pada saat hantaran bola dilakukan, sehingga seluruh anggata tubuh memiliki keseimbangan yang bagus.

\section{METODE}

Penelitian pengembangan model latihan shooting olahraga petanque ini menggunakan model penelitian dan pengembangan (research and development) dari Borg dan Gall yang terdiri dari sepuluh langkah dalam penelitian yakni sebagai berikut :

Research and information collecting (2) Planning (3) Develop preliminary form of product (4) Preliminary field testing (5) Main product revision (6) Main field testing (7) Operational product revision (8) Operational field testing (9) Final produk revision (10) Dissemination and implementation.

Menurut Borg dan Gall ada 10 tahapan dalam pengembangan model penelitian dan pengembangan. Adapun tahapan-tahapan tersebut dapat dilihat di tabel berikut:
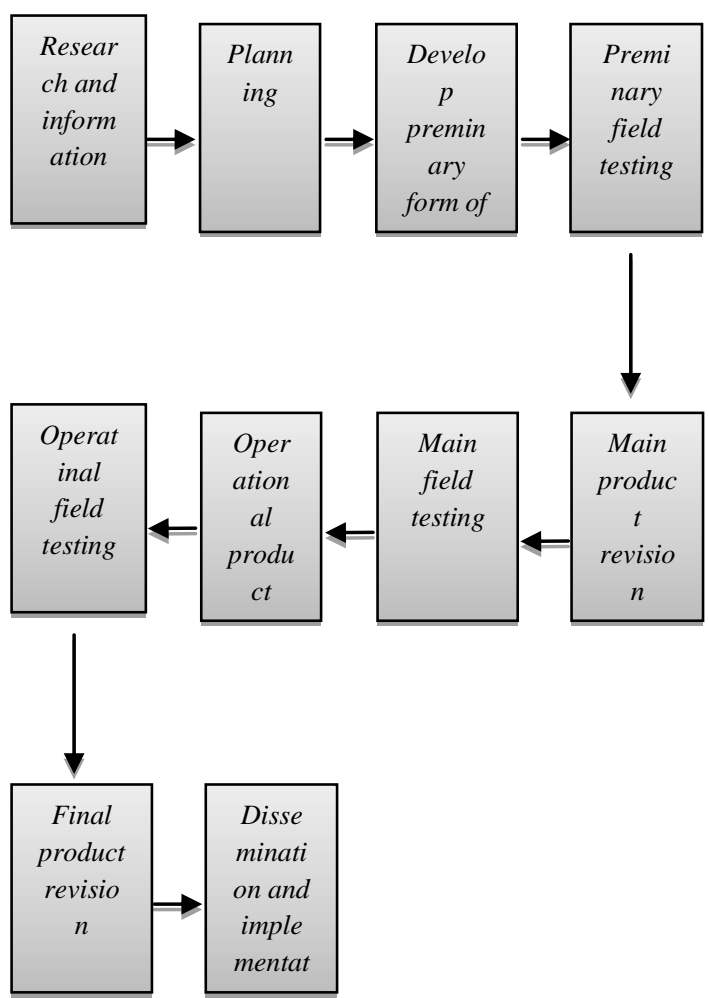

Gambar 1 Model Pengembangan Borg \& Gall Sumber: Walter R. Borg and Meredith D. Gall, Educational Research An Introduction (New York: Longman, 1983), h. 77. 
HASIL DAN PEMBAHASAN

Hasil Akhir Perbandingan Shooting Eksperimen dan Kontrol

Data penilaian dari 30 atlet terhadap efektivitas latihan shooting petanque dalam kelompok eksperimen dan 30 atlet terhadap efektivitas latihan shooting petanque dalam kelompok kontrol ditunjukkan pada tabel berikut ini:

Tabel 1. Hasil Shooting Kelompok Eksperimen dan Kelompok Kontrol

\begin{tabular}{|c|c|c|c|c|c|c|}
\hline Testee & $\begin{array}{c}\text { Pre-Test } \\
\text { Eksperimen }\end{array}$ & $\begin{array}{c}\text { Post-Test } \\
\text { Eksperimen }\end{array}$ & $\begin{array}{l}\text { Pre-Test } \\
\text { Kontrol }\end{array}$ & $\begin{array}{c}\text { Post-Test } \\
\text { Kontrol }\end{array}$ & Eksperimen & Kontrol \\
\hline Subjek 1 & 10 & 17 & 10 & 12 & 7 & 2 \\
\hline Subjek 2 & 15 & 19 & 11 & 14 & 4 & 3 \\
\hline Subjek 3 & 10 & 18 & 10 & 14 & 8 & 4 \\
\hline Subjek 4 & 12 & 22 & 12 & 15 & 10 & 3 \\
\hline Subjek 5 & 16 & 20 & 9 & 13 & 4 & 7 \\
\hline Subjek 6 & 10 & 19 & 13 & 15 & 9 & 3 \\
\hline Subjek 7 & 11 & 21 & 12 & 17 & 10 & 5 \\
\hline Subjek 8 & 17 & 22 & 9 & 14 & 5 & 2 \\
\hline Subjek 9 & 11 & 19 & 11 & 15 & 8 & 4 \\
\hline Subjek 10 & 9 & 16 & 10 & 15 & 7 & 7 \\
\hline Subjek 11 & 11 & 17 & 12 & 15 & 6 & 3 \\
\hline Subjek 12 & 9 & 13 & 12 & 18 & 4 & 6 \\
\hline Subjek 13 & 12 & 21 & 11 & 14 & 9 & 3 \\
\hline Subjek 14 & 14 & 19 & 9 & 13 & 5 & 4 \\
\hline Subjek 15 & 12 & 20 & 13 & 19 & 8 & 6 \\
\hline Subjek 16 & 13 & 19 & 12 & 15 & 6 & 3 \\
\hline Subjek 17 & 15 & 22 & 13 & 14 & 7 & 1 \\
\hline Subjek 18 & 12 & 16 & 11 & 16 & 4 & 5 \\
\hline Subjek 19 & 11 & 17 & 11 & 12 & 6 & 1 \\
\hline Subjek 20 & 12 & 17 & 12 & 16 & 5 & 6 \\
\hline Subjek 21 & 13 & 19 & 10 & 13 & 6 & 2 \\
\hline Subjek 22 & 10 & 19 & 9 & 14 & 9 & 4 \\
\hline Subjek 23 & 10 & 19 & 13 & 15 & 9 & 2 \\
\hline Subjek 24 & 14 & 22 & 12 & 13 & 8 & 1 \\
\hline Subjek 25 & 13 & 20 & 14 & 16 & 7 & 2 \\
\hline Subjek 26 & 9 & 14 & 12 & 14 & 5 & 2 \\
\hline Subjek 27 & 12 & 18 & 11 & 16 & 6 & 5 \\
\hline Subjek 28 & 12 & 19 & 14 & 15 & 7 & 1 \\
\hline Subjek 29 & 12 & 17 & 11 & 16 & 5 & 5 \\
\hline Subjek 30 & 9 & 16 & 12 & 15 & 7 & 3 \\
\hline$\Sigma$ & 356 & 557 & 341 & 443 & 201 & 105 \\
\hline
\end{tabular}


a. Nilai Rata - rata

Tabel 2. Nilai Rata - rata Shooting Kelompok Eksperimen

\begin{tabular}{cccccc} 
Kelompok & Mean & N & Srd.Dev & $\begin{array}{c}\text { Std. Eror } \\
\text { Mean }\end{array}$ \\
\cline { 2 - 5 } Nilai & Eksperimen & 6.70 & 30 & 1.822 & .333 \\
\cline { 2 - 5 } & Kontrol & 3.50 & 30 & 1.796 & .328
\end{tabular}

Berdasarkan hasil Output dengan menggunakan SPSS 16 dapat diketahui bahwa nilai rata -rata shooting kelompok kontrol adalah 3.50 artinya terdapat perbedaan dan nilai rata - rata kelompok eksperimen lebih tinggi dari nilai rata -rata kelompok kontrol.

\section{b. Signifikansi Perbedaan Shooting}

\section{Tabel 3. Signifikansi Perbedaan Shooting}

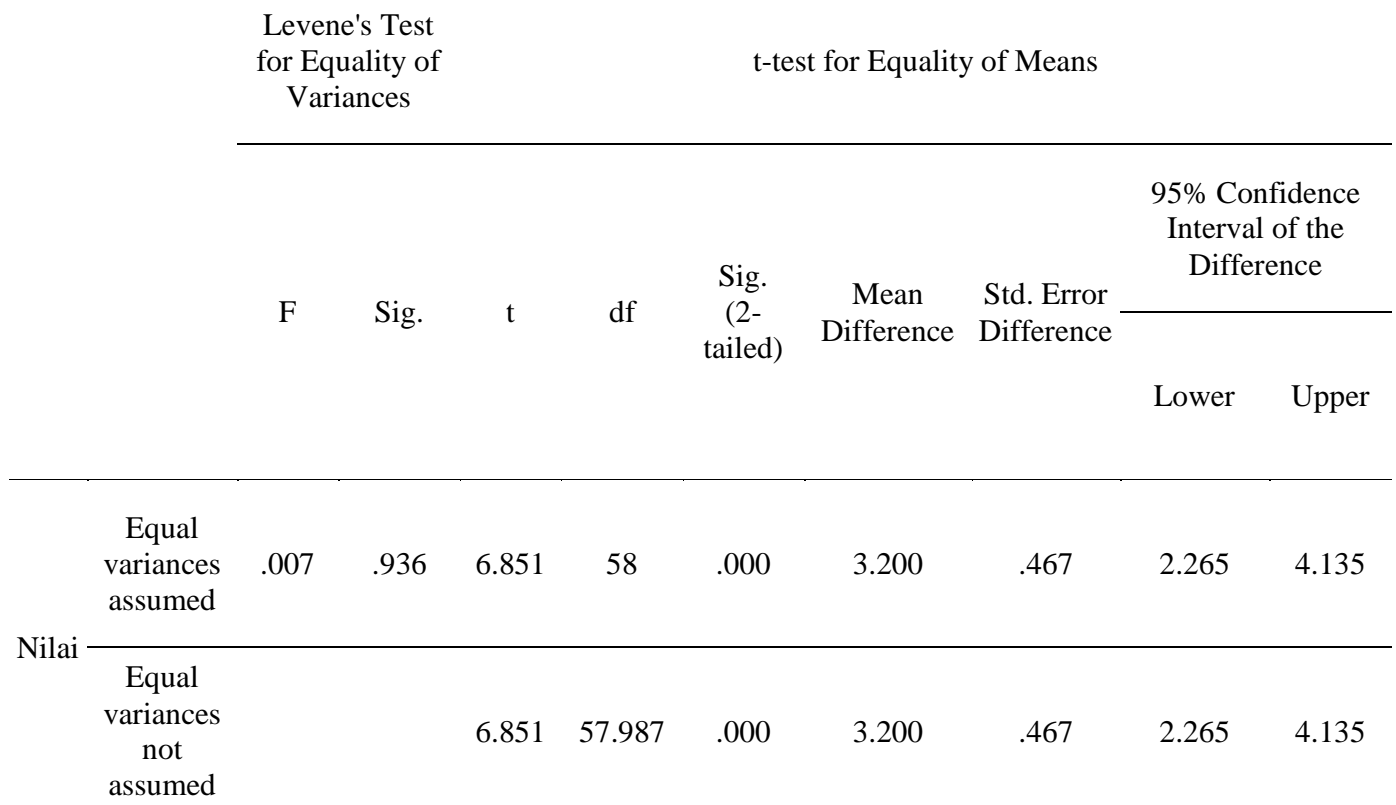

Dalam uji signifikan perbedaan dengan SPSS 16 terdapat hasil t-hitung $=6,851$, df $=58$ dan $\mathrm{p}$-value $=0,00<$ 0,05 yang berarti terdapat perbedaan yang signifikan antara hasil shooting kelompok eksperimen dan hasil kelompok kontrol.

Berikut perbandingan rata-rata hasil shooting dalam kelompok eksperimen dan rata-rata hasil shooting dalam kelompok control dalam bentuk diagram batang dan diagram pie pada gambar berikut :

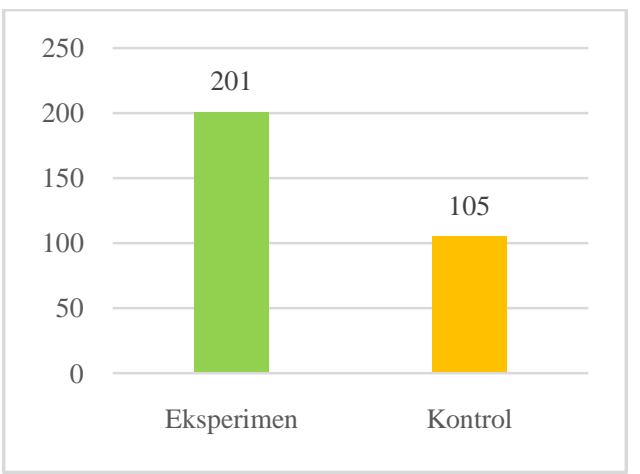

Gambar 2. Diagram Batang Hasil Shooting Kelompok Eksperimen dan Kelompok Kontrol 
Berdasarkan data yang diperoleh dan keterangan gambar di atas dapat dikatakan bahwa model latihan shooting olahraga petanque yang diberikan dalam kelompok eksperimen lebih efektif dalam meningkatkan latihan shooting olahraga petanque untuk atlet pemula dibandingkan dengan kelompok kontrol.

\section{HASIL DAN PEMBAHASAN}

Penyempurnaan Produk.

Berdasarkan perolehan angka pada tabel di atas dapat disimpulkan bahwa model latihan shooting olahraga petanque untuk atlet pemula dapat dan layak untuk digunakan dalam latihan shooting petanque untuk serta efektif untuk meningkatkan kemampuan shooting anak. Terdapat perbandingan angka yang menunjukan bahwasanya hasil dari tes awal dan tes akhir mengalami perkembangan, dari tes awal yang berjumlah 356 kemudian diberikan perlakukan berupa model-model latihan shooting yang sudah dikembangkan kemudian baru diadakan tes akhir atau post test untuk mengetahui efektivitas model yang dikembangkan dan diperoleh data berjumlah 557, jadi model latihan shooting petanque ini efektif untuk mengmbangkan latihan shooting olahraga petanque untuk atlet pemula.

Melihat kekurangan dan kelebihan dari produk yang dibuat terdapat masukan yang akan peneliti sampaikan demi tercapainya penyempurnaan produk ini, adapun masukannya adalah sebagai berikut:

a. Penggunaan peralatan yang lebih banyak dan memperhatikan kenyamanan serta keamanan dapat membuat anak lebih maksimal dalam melakukan gerakan-gerakan model shooting petanque yang di berikan oleh pelatih.

b. Karakteristik dan pemahaman atlet/siswa, mengharuskan pelatih memberikan praktik langsung kepada siswa untuk mempelajari gerak-gerak yang dirasakan baru untuk dilakukan.

Pembahasan Produk. Model shooting petanque yang dibuat oleh peneliti merupakan produk yang bertujuan untuk membantu pelatih dalam menyampaikan materi latihan shooting petanque, meningkatkan kemampuan shooting atlet/ siswa, dan sebagai referensi bahan latihan. Model shooting ini dibuat berdasarkan tingkat kebutuhan anak dalam aktvitas latihan khususnya teknik shooting dalam ekstrakulikuler petanque untuk pemula usia sekolah menengah atas.

Produk ini setelah dikaji mengenai beberapa kelemahan yang perlu pembenahan, maka dapat disampaikan beberapa keunggulan produk ini antara lain:

a. Meningkatkan shooting olahraga petanque atlet/siswa.

b. Model ini dapat menjadikan atlet/siswa lebih aktif, dan antusias dalam latihan shooting olahraga petanque.

c. Atlet/siswa dapat merasakan kenyamanan dan kemanan dalam proses latihan petanque di sekolah khususnya teknik shooting.

d. Model shooting petanque lebih efektif dan efisien

e. Dapat membantu pelatih dalam melatih atlet/siswa pada ektrakulikuler di sekolah.

f. Sumbangan bagi ilmu pengetahuan khususnya pendidikan jasmani disekolah

c. Model shooting petanque ini dilakukan secara sistematis dari hal yang mudah ke yang sulit.

d. Atlet/siswa juga dituntut untuk berpikir secara cepat, tepat.

e. Model yang digunakan sangat bervariatif yang dapat 
meningkatkan tingkat antusias atlet/siswa dalam latihan.

Keterbatasan

Produk.

Penelitian pengembangan ini telah diupayakan secara maksimal sesuai dengan kemampuan dari peneliti, namun dalam penelitian ini masih terdapat beberapa keterbatasan yang harus diakui dan dikemukakan sebagai bahan pertimbangan dalam menggeneralisir hasil dari penelitian yang dicapai.

Adapun

keterbatasan-

keterbatasan tersebut antara lain sebagai berikut:

a. Ujicoba lapangan penelitian ini akan lebih baik lagi apabila dilakukan pada lingkup yang lebih luas lagi

b. Produk yang digunakan masih jauh dari sempurna.

c. Sarana dan prasaran yang digunakan masih terbatas.

d. Penjelasan serta peraturan dalam model shooting petanque yang masih jauh dari kata sempurna.

e. Adanya factor-faktor psikologi yang ikut mempengaruhi hasil penelitian yang tidak dapat dikontrol, antara lain : minat, percaya diri, dan factor psikologis lainnya.

\section{PENUTUP}

Kesimpulan. Berdasarkan data yang diperoleh, dari hasil uji coba lapangan dan pembahasan hasil penelitian dapat disimpulkan bahwa :

1. Terdapat perbandingan angka yang menunjukan bahwasanya hasil dari tes awal dan tes akhir mengalami perkembangan, dari tes awal yang berjumlah 356 kemudian diberikan perlakukan berupa model-model latihan shooting yang sudah dikembangkan kemudian baru diadakan tes akhir atau post test untuk mengetahui efektivitas model yang dikembangkan dan diperoleh data berjumlah 557, jadi model latihan ini efektif untuk mengmbangkan latihan shooting untuk atlet pemula.

2. Dengan model latihan shooting olahraga petanque atlet pemula dapat berlatih shooting secara efektif dan efisien.

3. Dengan model latihan shooting yang telah peneliti kembangkan, atlet pemula dapat menguasai teknik shooting dengan tepat dan benar.

Saran. Pada bagian ini dikemukakan beberapa saran yang dikemukakan oleh peneliti sehubungan dengan produk yang dikembangkan. Adapun saran-saran yang dikemukakan meliputi saran pemanfaatan, saran deseminasi, dan saran pengembangan lebih lanjut.

\section{Saran Pemanfaatan}

Produk pengembangan ini adalah model latihan shooting olahraga petanque untuk pemula yang dapat digunakan sebagai rujukan oleh pelatih, guru, atlet maupun siswa. Dalam memanfaatkannya sangat perlu dipertimbangkan situasi, kondisi dan sarana prasarana.

\section{Saran Deseminasi}

Dalam penyebarluasan produk pengembangan kesasaran yang lebih luas, peneliti memberikan saran, antara lain:

a. Sebelum disebarluaskan sebaiknya produk ini disusun kembali menjadi lebih baik, baik itu tentang kemasan tampilan maupun isi dari materi produk yang dikembangkan.

b. Agar model latihan shooting olahraga petanque untuk pemula ini dapat digunakan, maka sebaiknya dicetak lebih banyak 
lagi, sehingga nantinya para pengguna dapat mengetahui dan mampu menguasai teknik shooting olahraga petanque dengan baik.

\section{Saran Pengembangan Lebih Lanjut}

Dalam mengembangkan penelitian ini ke arah lebih lanjut, peneliti mempunyai beberapa saran, sebagai berikut:

a. Untuk subyek penelitian sebaiknya dilakukan pada subyek yang lebih luas, baik itu di ekstrakurikuler maupun di klub-klub petanque selain yang digunakan sebagai kelompok ujicoba.

b. Hasil pengembangan model latihan shooting olahraga petanque untuk pemula ini dapat disebarluaskan ke sekolah maupun ke klub-klub petanque.

\section{DAFTAR PUSTAKA}

Apriyanto, David. Mengenal Tenis Meja. Jakarta Timur: Balai Pustaka, 2012.

Borg, W, R \& Meredith D. Gall. Educational Research An Introduction. New York: Longman, 1983.

Edwards, William H. Motor Learning and Control; From Theory to Practice. California: Sacramento, 2010.

Lanzoni, Ivan Malagoli., Rocco Di Michele and Franco Merni., "Technical and Tactical Performance of Top-Class Senior, Junior and Cadet Table Tennis Players," International Table Tennis Federation Sports Science Congress Conference Proceedings, Vol. 13 (8), 2013.
Lestari, Puji., "Kontribusi Kemampuan Backhand dan Forehand Drive ke Dinding Terhadap Kemampuan Bermain Tenis Meja Mahasiswa PJKR FKIP Universitas Bengkulu," Jurnal Ilmiah Pendidikan Jasmani, Vol. 1 (1), 2017.

Mahendra, Ika Rudi, Prapto Nugroho, dan Said Junaidi., "Kelentukan Pergelangan Tangan dan Koordinasi Mata Tangan dalam Pukulan Forehand Tenis Meja," Journal of Sport Sciences and Fitness, Vol. 1 (1), 2012.

Nelistya, Anne. Menjadi Juara Tenis Meja. Jakarta: Be Champion, 2011.

Permatasari, Dewi. Buku Pintar Tenis Meja. Jakarta Timur: Anugrah, 2017.

Santosa, Teguh., "Pengembangan Alat Bantu Return Board untuk Forehand Topspin Tenis Meja," Jurnal Pedagogik Keolahragaan, Vol. 2 (2), 2016

Sutarmin. Terampil Berolahraga Tenis Meja. Surakarta: Era Intermedia, 2007.

Widiastuti. Tes dan Pengukuran Olahraga. Jakarta: PT. Raja Grafindo, 2015. 